\title{
AWARENESS AND PRACTICE OF CONTRACEPTIVE METHODS AMONG MEN- A STUDY
}

\author{
Shailaja P1, Vidhya Rama R², Hema Malini P3
}

${ }_{1}^{1}$ Associate Professor, Department of Obstetrics and Gynaecology, ACSR Government Medical College, Nellore, Andhra Pradesh. ${ }^{2}$ Associate Professor, Department of Obstetrics and Gynaecology, ACSR Government Medical College, Nellore, Andhra Pradesh. ${ }_{3}^{3}$ Resident Doctor, Department of Obstetrics and Gynaecology, King George Hospital, Visakhapatnam, Andhra Pradesh.

\section{BACKGROUND}

\section{ABSTRACT}

Considerable gap exists between awareness and contraceptive use, which is more conspicuous in vasectomy. In a Government Hospital, tertiary health care centre where 6000 deliveries per year are taking place, the number of vasectomies are only 20 per year when compared to tubectomies which are 600 per year. Studies have found that there is an association between attitude towards family planning methods and use among men.

The aim of this study is to find the degree of awareness of modern family planning methods among men and to analyse the factors influencing their awareness and practice of vasectomy.

\section{MATERIALS AND METHODS}

The present study was carried out in the month of August 2017; 470 randomly selected married men who accompanied their wives, sisters, female friends or relatives to the department of family planning, King George Hospital, Visakhapatnam, AP were interviewed based on a pre-designed questionnaire. The questionnaire elicited information regarding their age, educational status, income, knowledge and practice of the modern contraceptive methods. As two of the 470 men belonged to the state of Odisha, they were excluded from the study. Results were analysed.

\section{RESULTS}

Nearly $100 \%$ of the study participants reported having heard of at least one method and about $90 \%$ reported awareness of at least five different methods of contraception. Analyses showed that educated men are more likely to have reported a high degree of awareness. Educated men though more informed (54\% - 30\%) are equal to men with low educational status when it comes to practice $(20.6 \%$ - 21\% IUCD above and below secondary school). Most commonly used male method is male condom (42.3\%). Some men are reluctant to use condom and often use it due to the fear of sexually transmitted diseases; $71.4 \%$ are unwilling to undergo vasectomy, as they believe that it may affect their sexual performance.

\section{CONCLUSION}

Men are the deciding authority in determining the size of the family in $99 \%$ of Indian families. There is need to sensitise the men in the community about the different modern FP methods to increase the acceptance and also help to correct the misconceptions regarding vasectomy. It is high time to concentrate on men, to practice family planning methods and to develop more male based family planning methods.

\section{KEYWORDS}

Men, IUCD, Vasectomy, Awareness, Practice.

HOW TO CITE THIS ARTICLE: Shailaja P, Rama VR, Malini HP. Awareness and practice of contraceptive methods among men- a study. J. Evolution Med. Dent. Sci. 2017;6(92):6583-6588, DOI: 10.14260/jemds/2017/1427

\section{BACKGROUND}

Family is very important in India and families tend to be very close knit. In India, people learn the essential themes of cultural life within the bosom of a family. In most part of the country, the basic units of society are the patrilineal family unit and wider kinship groupings. The most widely desired residential unit is the joint family, ideally consisting of three or four patrilineally related generations, all living under one roof; working, eating, worshiping and cooperating together in mutually beneficial social and economic activities. Since independence, joint families have become smaller.

'Financial or Other Competing Interest': None.

Submission 06-11-2017, Peer Review 23-11-2017,

Acceptance 25-11-2017, Published 04-12-2017.

Corresponding Author:

Dr. Shailaja $P$,

44/34/11-C,

Nandagiri Nagar,

Visakhapatnam-530016.

E-mail:pinjalashailaja@gmail.com

DOI: $10.14260 /$ jemds $/ 2017 / 1427$
Both nuclear and joint families are common nowadays. In the traditional Indian family, the eldest male governed the entire family. The daily life of its members revolved around this huge family. In good olden days, the females lived behind closed doors- "within the four walls" environs. Festive occasions were the only times when they had the opportunity to interact with others in the neighbourhood or relatives. Rural men have traditionally done heavy work such as ploughing, clearing trees, building homes as well as planting and sowing, while women have done the harvesting and gathering. Men also try to find work to bring in a modicum of income. Mostly husbands are bread winners and women generally take care of the household activities, besides bearing and rearing children. Traditionally, women rarely adapt the temporary methods of family planning and undergo tubectomy as a permanent method of contraception. Even though men are the decision makers in family, it is only the women who have to implement their decisions. Due to the constant efforts in making women aware of their rights and the importance of their involvement in a day-to-day family matters, the status of women has increased significantly. Due 
to all these measures, women nowadays actively participate not only in their family affairs but also in social and political activities in the communities. In spite of these changes initiated for the benefit of women in India, the people's attitude to equal status for women has not changed significantly in actual practice.(1) Male involvement in regulating family size has been a concern for the health policy makers for quite some time. As male parents are also responsible for the rearing of children, it is expected that they should have a role in planning the size of the family, prevent sexually transmitted diseases and other health complications. The role of men in such matters is of great importance in India, because the sole decision-makers in a vast majority of the Indian families are men. Especially in the developing countries, women have a little or no say on matters which affect their reproduction or reproductive health. They need the consent of their husbands before accessing to health care or using contraception. Very little research has been focussed on men.(2) Exploring men's reproductive health knowledge is particularly important in a developing country like India, where most women have limited control over their lives and are completely dependent on husbands. Keeping this background in view, the present study has been undertaken with the following specific objectives.

\section{Objectives}

- $\quad$ To assess the knowledge and practice of various family planning methods among men.

- To project the difference in knowledge and practice of various methods.

- To assess the factors that prevent men to undergo vasectomy.

\section{Review of Literature}

There are many family planning programs being implemented worldwide to reduce population growth. These programs spread the use of modern family planning methods, such as pills and IUCD. These programs help people achieve their personal reproductive goals. Most family planning programs are targeting women and interventions have been to address and mitigate barriers to the use of family planning. Attitudinal resistance remains a barrier to practice and access to contraceptives.(3) Many studies and interventions have been done to increase the use of modern family planning methods among women; however, the progress is still low. The effectiveness and utilisation of modern family planning methods among women is poor due to lack of approval from their partners/ husbands.(4) The roles and responsibilities of men in the use of modern family planning methods and fertility regulations has been ignored, understudied and underutilised, yet sociological factors such as culture and religion are in favour of men as decisionmakers both at family levels and community levels. Family planning methods are not being utilised in the community and is mostly attributed to the lack of male involvement. The findings revealed that many men are aware of family planning and its benefits to them and their families. However, the level of practice among the men was low. The commonly used family planning method by men is condoms. Men are hesitant to accept their women to use modern family planning methods due to the perceived risks of using these methods. There is misconception about the risks in family planning among the men attributing cancer and irregular uterine bleeding to the hormonal methods and intrauterine contraceptive devices respectively. Cultural and religious beliefs also play a negative role in the acceptance of the modern family planning methods. Studies also showed that men would demand their women discontinue modern family planning methods when used without their consent.(5) All in all, there is need to educate and involve men into family planning since they are aware that it is beneficial but have limited information to make an informed decision about the use of modern family planning methods by them and their wives.

For many years family planning program planners have focused attention largely on women's attitudes and behaviours in matters concerning family planning, since it is women who become pregnant and face the health risks associated with pregnancy. Though women are using contraceptive methods that require male involvement such as condoms, periodic abstinence, withdrawal and vasectomy are less used. Furthermore, family planning programs have less attention towards the understanding of men's role in the effective and consistent utilisation of contraceptive methods.(5) Men's fertility intentions, reproductive preferences and their attitude towards family planning influence the fertility behaviour of their wives and their attitudes toward the use of modern contraceptives.(6) Hence, in order to increase the use of modern contraceptives, family planning programs need to target men specifically at all levels of the program. Several factors such as the fear of contraceptives and their side effects, preference for sons, low socioeconomic status of women and age old beliefs are responsible for the poor acceptance of family planning. It is necessary that male-specific family planning programs are designed and implemented.(7) There is an existing gap globally on the attitudes and willingness of men towards modern family planning methods. In addition, understanding the attitude and willingness of men towards modern family methods may increase contraceptive use by their women also.(4) A large proportion of men have heard of family planning; however, few know about all the available family planning methods. The commonly known modern family planning methods among men are condoms, pills and tubectomy, while very little is known about IUCD or vasectomy. Most men are not aware that the use of modern family planning methods can help the man and his wife avoid unwanted pregnancy, space their children well and be able to provide for them. They still do not understand a well-spaced child birth enables them to feed, care and educate their children better. Despite the many advantages of the IUD as a method of family planning, it generally suffers from unpopularity worldwide with the exception of a few countries like China, Egypt, Mexico and Turkey. The scenario in India is the same with less than two percent of currently women adopting the IUD as a method of contraception. ${ }^{(8)}$ An integrated approach to male involvement is needed. Some studies supported school-based clinics as a venue to involve male adolescents in contraceptive decision making.(9)

\section{MATERIALS AND METHODS}

This study is conducted from March 2017 to August 2017 (six months) and 470 married men whoever attended the family 
planning OP accompanying their wives, sisters, female friends and relatives to the Department of Family Planning, King George Hospital, Visakhapatnam, AP are interviewed based on a pre-designed questionnaire. The questionnaire elicited information regarding their age, educational status, income, knowledge and practice of the modern contraceptive methods. Two men belonging to the state of Odisha are excluded from the study. Results are analysed by SPSS version 15.0 using chi-square test.

\section{RESULTS}

\begin{tabular}{|c|c|c|c|}
\hline Variables & & Frequency & Percent \\
\hline \multirow{3}{*}{ Age } & $25-30$ years & 251 & 53.6 \\
\hline & $31-35$ years & 199 & 42.6 \\
\hline & Above 36 years & 18 & 3.8 \\
\hline \multirow{3}{*}{$\begin{array}{c}\text { Area of } \\
\text { Residence }\end{array}$} & Rural & 243 & 53.0 \\
\hline & Urban & 116 & 24.8 \\
\hline & Urban Slum & 109 & 22.2 \\
\hline \multirow{4}{*}{ Religion } & Hindu & 215 & 45.9 \\
\hline & Muslim & 46 & 9.8 \\
\hline & Christian & 170 & 36.3 \\
\hline & Others & 37 & 7.5 \\
\hline \multirow{5}{*}{ Education } & Illiterates & 62 & 13.2 \\
\hline & Primary & 145 & 30.9 \\
\hline & Secondary & 188 & 40.3 \\
\hline & Degree & 64 & 13.7 \\
\hline & Postgraduation & 9 & 1.9 \\
\hline \multirow{5}{*}{ Occupation } & Labourer & 188 & 40.1 \\
\hline & Unskilled Worker & 125 & 26.8 \\
\hline & Skilled Worker & 64 & 13.7 \\
\hline & Professional & 18 & 3.8 \\
\hline & Business & 73 & 15.6 \\
\hline \multirow{3}{*}{$\begin{array}{l}\text { Number of } \\
\text { Children }\end{array}$} & One & 216 & 46.2 \\
\hline & Two & 207 & 44.2 \\
\hline & More than Two & 45 & 9.6 \\
\hline Tabl & Frequency Distr & ution of Var & les \\
\hline
\end{tabular}

Maximum number of men in this study belong to the age group of 25 - 35 (99.2\%); 53\% are from rural area and $47 \%$ are from urban and urban slums, as this is a tertiary care centre. At least $40.3 \%$ have a minimum of secondary education.

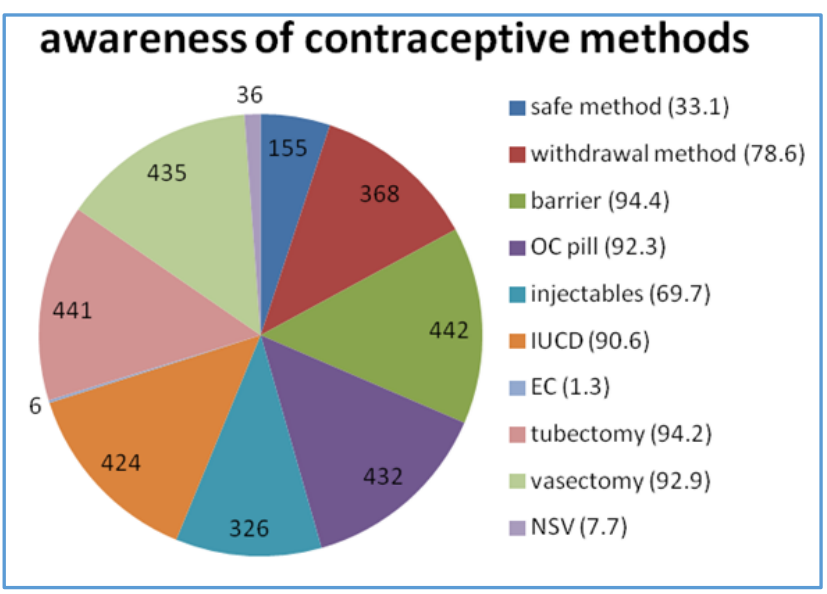

Figure 1. Awareness of the various Contraceptive Methods
This chart shows that maximum number of men are well aware about both the permanent and temporary methods of contraception. But awareness about the newer methods like no-scalpel vasectomy and the emergency contraception is quite poor.

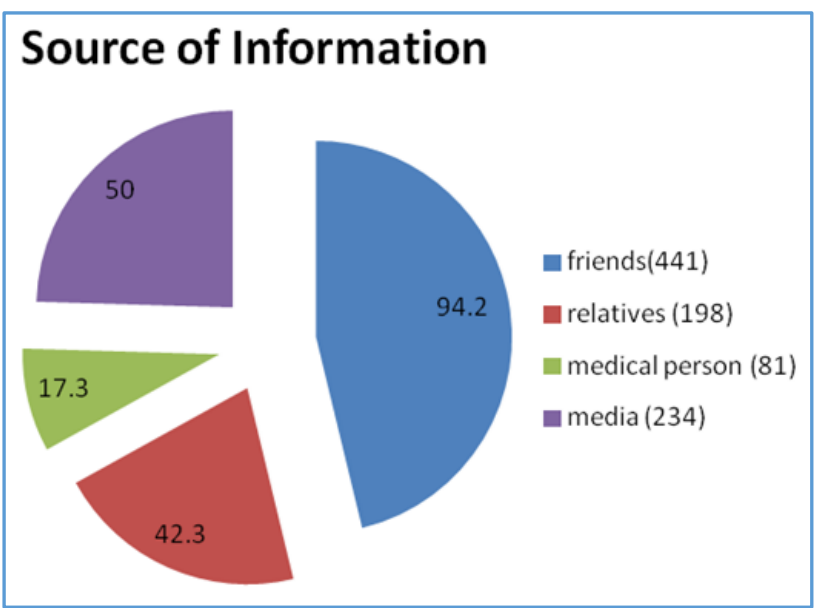

Figure 2. Source of Information about the FP Methods

Maximum number of men, that is $94.2 \%$ gather information from their friends.

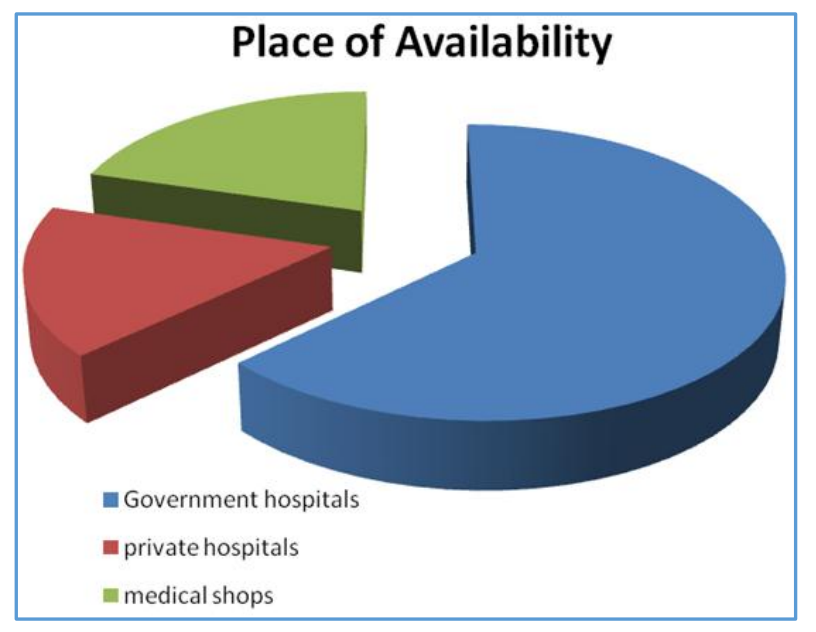

Figure 3. Place of Availability of Contraceptive Methods

Maximum men still believe that family planning is only a government programme and information and the services are available with the government hospitals.

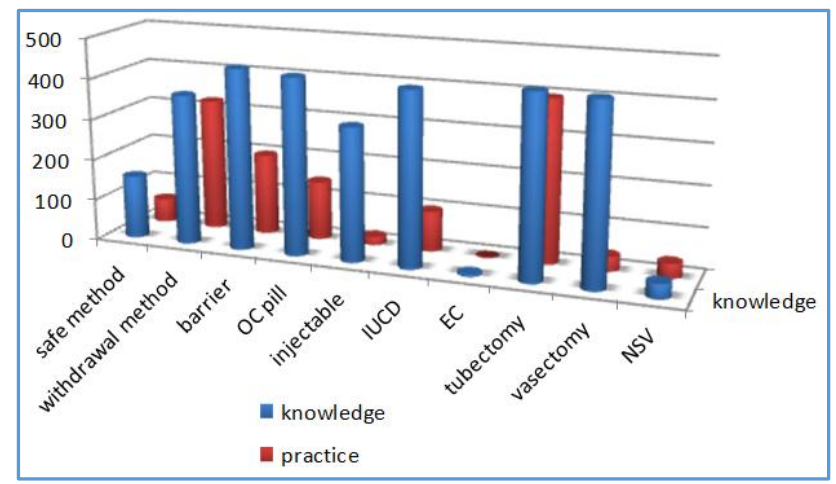

Figure 4. Comparison of Awareness and Practice of various Methods of Contraception 
Though the awareness of the contraceptive methods among men is good enough when it comes to practice, they are more in favour of the permanent methods. In the permanent methods too, practice of tubectomy $(94.2 \%$ awareness and $884.6 \%$ practice) is good when compared to vasectomy ( $92.3 \%$ awareness and $7.7 \%$ practice). Only $30.8 \%$ of men are willing for the use of oral contraceptive pills by their wives and when it comes to the use of IUCDs it is even more less $21.2 \%$.

\begin{tabular}{|c|c|c|}
\hline Response & Yes & No \\
\hline Avoiding unwanted pregnancy & $162(34.6)$ & $306(65.4)$ \\
\hline Spacing between pregnancy & $162(34.6)$ & $306(65.4)$ \\
\hline Number of children & $371(79.3)$ & 97 (20.7) \\
\hline
\end{tabular}

$79.3 \%$ of men are of the opinion that having a small family means to restrict the number of children to either two or three. Only $1 / 3$ are aware of avoiding unintended pregnancies and closely spaced pregnancies.

\begin{tabular}{|c|c|c|}
\hline Reasons & Yes & No \\
\hline Fear of surgery & $199(42.5)$ & $269(57.5)$ \\
\hline Fear of complication & $218(46.6)$ & $250(53.4)$ \\
\hline Unaware & $36(7.7)$ & $432(92.3)$ \\
\hline Loss of libido & $334(71.4)$ & $134(28.6)$ \\
\hline Job of wife & $10(2.1)$ & $458(97.9)$ \\
\hline \multicolumn{2}{|c|}{ Table 3. Reasons for not accepting Vasectomy } \\
\hline
\end{tabular}

$92.3 \%$ are not willing to undergo vasectomy, $71.4 \%$ have the fear of losing libido, $46.6 \%$ are afraid of complications (that is whether they can do their work or not), $2.1 \%$ still believe that it is the job of their wives.

\begin{tabular}{|c|c|c|}
\hline Awareness & Yes & No \\
\hline Need to control population & $396(84.6)$ & $72(15.4)$ \\
\hline $\begin{array}{c}\text { Negative impact of overpopulation } \\
\text { on our happiness }\end{array}$ & $18(3.8)$ & $450(96.2)$ \\
\hline $\begin{array}{c}\text { Responsibility to control } \\
\text { overpopulation }\end{array}$ & $243(51.9)$ & $225(48.1)$ \\
\hline $\begin{array}{c}\text { Impact on resources due to } \\
\text { overpopulation }\end{array}$ & $18(3.8)$ & $450(96.2)$ \\
\hline \multicolumn{3}{|c|}{ Table 4. Awareness about Overpopulation } \\
\hline \multicolumn{3}{|c}{} \\
\hline
\end{tabular}

\begin{tabular}{|c|c|c|c|c|c|c|}
\hline \multirow[b]{2}{*}{ Variables } & \multicolumn{3}{|c|}{ Knowledge } & \multicolumn{3}{|c|}{ Practice } \\
\hline & & & & & & \\
\hline Age & Yes & No & P-value & Yes & No & P-value \\
\hline $25-30$ years $(251)$ & 236 & 15 & \multirow{3}{*}{0.853} & 0 & 251 & \multirow{3}{*}{$0.000^{* *}$} \\
\hline 31-35 years (199) & 181 & 18 & & 20 & 179 & \\
\hline Above 36 years (18) & 17 & 1 & & 16 & 2 & \\
\hline \multicolumn{7}{|l|}{ Area } \\
\hline Rural (243) & 234 & 9 & \multirow{3}{*}{$0.000^{* *}$} & 18 & 225 & \multirow{3}{*}{0.931} \\
\hline Urban (116) & 101 & 15 & & 9 & 107 & \\
\hline Urban Slum (109) & 99 & 10 & & 9 & 100 & \\
\hline \multicolumn{7}{|l|}{ Religion } \\
\hline Hindu (215) & 206 & 9 & \multirow{4}{*}{$0.000^{* *}$} & 30 & 185 & \multirow{4}{*}{$0.000^{* *}$} \\
\hline Muslim (46) & 45 & 1 & & 0 & 46 & \\
\hline Christian (170) & 155 & 15 & & 6 & 164 & \\
\hline Others (37) & 28 & 9 & & 0 & 37 & \\
\hline \multicolumn{7}{|l|}{ Education } \\
\hline Illiterate (62) & 47 & 15 & \multirow{5}{*}{$0.000^{* *}$} & 0 & 62 & \multirow{5}{*}{$0.000^{* *}$} \\
\hline Primary (145) & 136 & 9 & & 0 & 145 & \\
\hline Secondary (188) & 187 & 1 & & 7 & 181 & \\
\hline Degree (64) & 55 & 9 & & 20 & 44 & \\
\hline PG (9) & 9 & 0 & & 9 & 0 & \\
\hline \multicolumn{7}{|l|}{ Occupation } \\
\hline Labourer (188) & 164 & 24 & \multirow{5}{*}{$0.000^{* *}$} & 3 & 185 & \multirow{5}{*}{$0.000^{* *}$} \\
\hline Unskilled Worker (125) & 125 & 0 & & 0 & 125 & \\
\hline Skilled Worker (64) & 54 & 10 & & 5 & 59 & \\
\hline Professional (18) & 18 & 0 & & 18 & 0 & \\
\hline Business (73) & 73 & 0 & & 10 & 63 & \\
\hline \multicolumn{7}{|l|}{ No. of Children } \\
\hline One (216) & 207 & 9 & \multirow{3}{*}{$0.000^{* *}$} & 0 & 216 & \multirow{3}{*}{$0.000^{* *}$} \\
\hline Two (207) & 183 & 24 & & 20 & 187 & \\
\hline ? Two (45) & 44 & 1 & & 16 & 29 & \\
\hline & Tal & en & of Vas & pari & & \\
\hline
\end{tabular}

This shows that education, occupation and religion are the variables that affect the acceptance for vasectomy among men in this study. 


\begin{tabular}{|c|c|c|c|c|c|c|}
\hline \multirow[b]{2}{*}{ Variables } & \multicolumn{3}{|c|}{ Knowledge } & \multicolumn{3}{|c|}{ Practice } \\
\hline & & & & & & \\
\hline Age & Yes & No & P-value & Yes & No & P-value \\
\hline 20-25 years & $90(35.7)$ & $161(64.3)$ & \multirow{3}{*}{$0.00^{* *}$} & $54(21.4)$ & $197(78.6)$ & \multirow{3}{*}{$0.007^{*}$} \\
\hline $25-30$ years & 63 (31.8) & $136(68.2)$ & & $36(18.2)$ & $163(81.8)$ & \\
\hline Above 30 years & $18(100.0)$ & $0(0.0)$ & & $9(50.0)$ & $9(50.0)$ & \\
\hline \multicolumn{7}{|l|}{ Area } \\
\hline Rural & 81 (33.3) & $162(66.7)$ & \multirow{3}{*}{0.288} & $63(25.9)$ & $180(74.1)$ & \multirow{3}{*}{$0.001^{* *}$} \\
\hline Urban & $45(38.5)$ & $71(61.5)$ & & $27(23.1)$ & $89(76.9)$ & \\
\hline Urban Slum & 45 (41.7) & $64(58.3)$ & & $9(8.3)$ & $100(91.7)$ & \\
\hline \multicolumn{7}{|l|}{ Religion } \\
\hline Hindu & $99(45.8)$ & $116(54.2)$ & \multirow{4}{*}{$0.000^{* *}$} & $63(29.2)$ & $152(70.8)$ & \multirow{4}{*}{$0.000^{* *}$} \\
\hline Muslim & $18(40.0)$ & $28(60.0)$ & & $18(40.0)$ & $28(60.0)$ & \\
\hline Christian & $45(26.3)$ & $125(73.7)$ & & $9(5.3)$ & $161(94.7)$ & \\
\hline Others & $9(25.0)$ & $28(75.0)$ & & $9(25.0)$ & $28(75.0)$ & \\
\hline \multicolumn{7}{|l|}{ Education } \\
\hline Illiterate & $9(14.3)$ & $53(85.7)$ & \multirow{5}{*}{$0.000^{* *}$} & $0(0.0)$ & $62(100.0)$ & \multirow{5}{*}{$0.000^{* *}$} \\
\hline Primary & $\begin{array}{c}54 \\
(37.5) \\
\end{array}$ & $91(60.5)$ & & 45 (31.3) & $100(68.8)$ & \\
\hline Secondary & $81(42.9)$ & $101(57.1)$ & & $36(19.0)$ & $152(81.0)$ & \\
\hline Degree & $18(28.6)$ & $46(71.4)$ & & $9(14.3)$ & 55 (85.7) & \\
\hline PG & $9(100.0)$ & $0(0.0)$ & & $9(100.0)$ & $0(0.0)$ & \\
\hline \multicolumn{7}{|l|}{ Occupation } \\
\hline Labourer & $54(28.6)$ & $134(71.4)$ & \multirow{5}{*}{$0.000^{* *}$} & $45(23.8)$ & $143(76.2)$ & \multirow{5}{*}{$0.000^{* *}$} \\
\hline Unskilled Worker & $54(42.9)$ & $71(57.1)$ & & $9(7.1)$ & $116(92.9)$ & \\
\hline Skilled Worker & $27(42.9)$ & 37 (57.1) & & $18(28.6)$ & $46(71.4)$ & \\
\hline Professional & $18(100.0)$ & $0(0.0)$ & & $9(50.0)$ & $9(50.0)$ & \\
\hline Business & $18(25.0)$ & $55(75.0)$ & & $18(25.0)$ & $55(75.0)$ & \\
\hline \multicolumn{7}{|l|}{ No. of Children } \\
\hline None & $81(37.5)$ & $135(62.5)$ & \multirow{3}{*}{$0.001^{* *}$} & $63(29.2)$ & $153(70.8)$ & \multirow{3}{*}{$0.000^{* *}$} \\
\hline One & $63(30.4)$ & $144(69.6)$ & & $27(13.0)$ & $180(87.0)$ & \\
\hline Two & $27(60.0)$ & $18(40.0)$ & & $9(20.0)$ & $36(80.0)$ & \\
\hline
\end{tabular}

\section{DISCUSSION}

The study group consisted of randomly selected men who visited the family planning OP with their female patients, therefore all are in the age group above 25 years. As the hospital is a referral centre, men from rural and urban areas are almost equal in number (53\% - 47\%); 46 percent of men belonged to Hindu community; $55.9 \%$ are above secondary school education and $13.2 \%$ illiterates (learned only to write name); $40.1 \%$ are labourers who belonged to the low income group. Overall, awareness of temporary and permanent methods of family planning is reasonably good (94\%). Newer methods like emergency contraception and injectable form of hormonal contraceptives are not popular (> 5\%). Information about the family planning methods are mostly obtained from friends and media. Accessibility of electronic media to the very interior villages may be the cause that people are kept well informed irrespective of the residence. Maximum (63\%) men are of the opinion that contraceptives are available only in the Government Hospitals, that is they are of the opinion that family planning is promoted by the Government. Even after 65 years after launching the programme of family planning, there is still a wide gap between awareness and practice of most of the FP methods. When it comes to permanent methods, men are of the opinion that only their wives should undergo surgery. Very few men (7.7) are aware of the no-scalpel technique of vasectomy. Though most of the men are aware about vasectomy, very few are willing to undergo vasectomy $(92.4 \%-7.7 \%)$. Out of the 36 men who underwent or willing to undergo vasectomy are either for the extra incentive or for the job purpose (police department- 23 out of 36) or wife unfit (10 out of 36). More than $70 \%$ of men are afraid of sexual performance after vasectomy and $46.6 \%$ are afraid of inability to do heavy work/ earn their living.

\section{CONCLUSION}

Most of the family planning programmes are targeting women because it is the woman who conceive, carry and are exposed to the complications of pregnancy. Many interventions have been done to increase usage of the modern family planning methods among women. The roles and responsibilities of men in the use of modern family planning methods and fertility regulations has been ignored, understudied and underutilised, though sociological factors such as culture and religion are in favour of men as decision makers both at family level and community level. It is high time now to educate and involve men into family planning. Shattuck et al 2011 confirmed that male involvement may increase contraceptive use.(10) Misconceptions about vasectomy have to be addressed and have to be alleviated.

\section{REFERENCES}

[1] Chowdhury A, Patnaik MM. Understanding Indian family life: the gender perspective. EIJMMS 2013;3(7):58-67.

[2] Jayalakshmi MS, Ambwani K, Prabhakar PK, et al. A study of male involvment in family planning. Health and Population-Perspectives and Issues 2002;25(3):113-23. 
[3] Cleland JG, Ndugwa RP, Zulu EM. Family planning in sub-Saharan Africa: progress or stagnation? Bull World Health Organ 2011;89:137-43.

[4] Tawiah EO. Factors affecting contraceptive use in Ghana. J Biosoc Sci 1997;29(2):141-9.

[5] Ijadunola MY, Abiona TC, Ijadunola KT, et al. Male involvment in family planning decision making in IleIfe, Osun state Nigeria. Afr J Reprod Health 2010;14(4 Spec no):43-50.

[6] Mesfin G. The role of men in fertility and family planning program in Tigray region. Ethopian Journal of Health Development 2002;16(3):247-55.

[7] Zeyneloğlu S, Kısa SK, DelibaŞ L. Determinants of family planning use among Turkish married men who live in south east Turkey. Am J Men's Health 2013;7(3):255-64.
[8] Khan ME, Mukharjee N, Kar SS, et al. Increasing the accessibility, acceptability and use of IUD in Gujarat, India. New Delhi, India: Population Council. Frontier Final Report 2008.

[9] Edwards SR. The role of men in contraceptive decision making: current knowledge and future implications. Fam Plann Perspect 1994;26(2):77-82.

[10] Shattuck D, Kerner B, Gilles MSK, et al. Encouraging contraceptive uptake by motivating men to communicate about family planning: the malawi male motivator project. Am J Public Health 2011;101(6):1089-95. 